\title{
Causes of Visual Impairment in the Bolgatanga Municipality in the Upper East Region of Ghana
}

\author{
Justice Ablordey Akpabla ${ }^{1 *}$ and Isabel Signes-Soler ${ }^{1,2}$ \\ ${ }^{1}$ Department of Optometry, School of Advanced Education, Research and Accreditation, S.L, (SAERA), Spain \\ ${ }^{2}$ Department of Optics and Optometry and Vision Sciences, University of Valencia, Valencia Spain
}

Submission: March 05, 2019; Published: April 01, 2019

*Corresponding author: Justice Ablordey Akpabla, Department of Optometry, School of Advanced Education, Research and Accreditation, S.L, (SAERA), Spain

\begin{abstract}
Objective: To profile the causes of visual impairment in the Bolgatanga municipality.

Method: A retrospective study was conducted at the Presbyterian Regional Eye Hospital in Bolgatanga, Upper East region from October 2017 through April 2018. New cases aged 6 years and above, were included in this study based on presenting distance visual acuity. The variables, presenting distance visual acuity, primary diagnosis, refractive error status and demographic data were obtained from patients' records and analyzed using SPSS, Version16.2 (version 16.2, SPSS, Inc., Chicago, IL, USA). The data obtained were analyzed descriptively while a Chi-squared test was used to analyze the strengths of association between qualitative where $\mathrm{P}<0.05$ denoted a statistical significance.

Results: Out of the 4659 new cases reviewed, 1323 were included in the study giving an overall calculated prevalence of visual impairment of $28.4 \%$. The mean age was $60.44 \pm 19.66$ years. The prevalence rates of the different grades of visual impairment were found to be: $63.9 \%$ for moderate visual impairment (MVI), 4.9\% for Severe Visual Impairment (SVI), and 28.9\% for blindness. The leading causes of low vision were cataract, uncorrected refractive error, glaucoma, and corneal-related disorders while the main causes of blindness were cataract, glaucoma, and corneal-related disorders.
\end{abstract}

Conclusion: There is a high prevalence of visual impairment in the Bolgatanga Municipality and most of the causes are treatable. Older age, unemployment, being a female (gender) and being a widow/widower (marital status) are the socio-demographic risk factors identified.

Keywords: Visual Impairment; Blindness; Low vision; Glaucoma; Cataract; Corneal related Disorder

Abbreviations: MVI: Moderate Visual Impairment; SVI: Severe Visual Impairment

\section{Introduction}

Visual impairment is a public health problem with devastating effect on the quality of life of affected persons. It presents educational, occupational and social challenges, with affected persons being at a higher risk of behavioral, psychological and poor social integration [1-3].

The global distribution of visual impairment and blindness is disproportionate with the Sub-Saharan African region having higher prevalence rates. The Western Sub-Saharan Region, of which Ghana is one of the 19 countries, is second to Southern Asia in the global regional prevalence of blindness and visual impairment (5.58\%) with major causes identified as: Uncorrected Refractive error (41.36\%), Cataract (33.44\%), Glaucoma (4.94\%), Age Related Macular Degeneration (2.90\%), Trachoma (2.58\%), Corneal Opacities (2.41\%), Others (11.96\%) [3-5].
The Ghana National Blindness and Visual Impairment Study (GBVIS), 2015, estimated the prevalence of blindness and severe visual impairment in the country at $0.74 \%$ and $1.07 \%$ respectively with high prevalence in the rural areas $(0.79 \%)$ than in the urban areas $(0.67 \%)$. Cataract $(54.8 \%)$ followed by glaucoma $(19.4 \%)$ were identified as the main causes of blindness. Uncorrected refractive error $(44.4 \%)$, followed by cataract $(42.2 \%)$ were identified as the main causes of visual impairment [5].

One major limitation in the elimination of avoidable visual impairment is the paucity of data on the causes of visual impairment in the different populations and age groups [7-9]. This study seeks to profile the causes of visual impairment in the Bolgatanga Municipality in the Upper East region of Ghana, which will serve as a baseline in designing programs and policy interventions. 


\section{Materials and Methods}

\section{Study design}

This was a retrospective review of charts of patients who visited the Presbyterian Regional Eye Hospital in Bolgatanga, for the first time from October 2017 through April 2018.

\section{Study site}

The Upper East region is located in the North-Eastern corner of Ghana between Longitude $0^{\circ}$ and $1^{\circ}$ West and Latitudes $10^{\circ}$ $30^{\prime \prime}$ North and $11^{\circ}$ North, within the Meningitis Belt of Africa and the Savannah blinding onchocerciasis belt of West Africa [11,12]. About $87 \%$ of the population of the region is rural and scattered in dispersed settlements [11]. The region is divided into 15 administrative districts with Bolgatanga municipal as its capital, which is also the center of population in the entire region with a population size of 131,550 in the year 2010 [11]. There are nine eye care facilities in the region, among which the Presbyterian Regional Eye Hospital in the Bolgatanga Municipality, has a complete team of eye care professionals (a visiting Ophthalmologist, Optometrist, Ophthalmic nurses, and Optician), and thus serves as a primary and a referral eye care center within the entire region, hence was selected for this study.

\section{Sampling}

Only new cases were included in this study. This is to determine the true burden and causes of visual impairment within the municipal among eye care seekers. Based on the daily out-patient attendance, an estimated population of about 3000 records was expected. The categorization of visual impairment used was based on the 10th revision of the International Statistical Classification of Diseases, Injuries and Causes of Death (ICD - 10, 2016) [6].

A total of 4659 records of new cases that had undergone comprehensive ophthalmic examinations: distance and near visual acuity testing, slit lamp bio-microscopy (anterior and posterior eye examination) examination, intraocular pressure measure- ment, automated visual field testing (for those suspected of Glaucoma), objective refraction, subjective refraction were reviewed for the period of October, 2017 through to April, 2018. A total sample of 1323 cases, aged 6 years and above, with a presenting distance visual acuity of $6 / 18$ or worse in the better seeing eye with or without correction, and or a presenting distance visual acuity better than or equal to $6 / 12$ in the better seeing eye but near visual acuity worse than $N 8$, were included in the study $[2,3]$. The variables: age, gender, marital status, occupation/employment status, and health care affordability/ health insurance membership, presenting visual acuity, primary diagnosis and refractive error status, were obtained from patients' records.

\section{Ethical consideration}

The study was in accordance with the Belmont Report which promotes respect for persons, beneficence and justice. Based on the International Ethical Guidelines for Epidemiological Studies recommendations, [13] an ethical clearance was obtained from the Navrongo Health Research Centre, an Institutional Review Board. Further official permission was obtained from the administration of the Presbyterian Eye Hospital for access to the facility's out-patient records. To ensure the confidentiality and anonymity of data collected and the patients' names, chart numbers, and any form of identification were not recorded or included in the data collected and the analysis.

\section{Results}

A Statistical Package for Social Sciences (version 16.2, SPSS, Inc., Chicago, IL, USA) was used to analyse the data collected descriptively while a Chi-squared test was used to analyse the strengths of association between qualitative where $\mathrm{P}<0.05$ denoted a statistical significance.

\section{General overview of the demographic characteristics of the population}

The general characteristics of the population are shown in Table 1 .

Table 1: Frequency Distribution of Demographic Characteristics.

\begin{tabular}{|c|c|c|}
\hline Demography & \multicolumn{2}{|c|}{ Characteristics } \\
\hline \multicolumn{3}{|c|}{ Age } \\
\hline Mean $( \pm$ Std $)$ & \multicolumn{2}{|c|}{$60.44 \pm 19.663$} \\
\hline Range (Minimum \& Maximum) & \multicolumn{2}{|c|}{$99(6-105)$} \\
\hline Age Groups & Frequency (n) & Percent (\%) \\
\hline $6-20$ & 95 & 7.2 \\
\hline $21-30$ & 46 & 3.5 \\
\hline $31-40$ & 68 & 5.1 \\
\hline $41-50$ & 158 & 11.9 \\
\hline $51-60$ & 195 & 14.7 \\
\hline$>61$ & 761 & 57.5 \\
\hline Gender & Frequency (n) & Percent (\%) \\
\hline Female & 773 & 58.4 \\
\hline Male & 550 & 41.5 \\
\hline
\end{tabular}


JOJ Ophthalmology

\begin{tabular}{|c|c|c|}
\hline Marital Status & Frequency (n) & Percent (\%) \\
\hline Single & 135 & 55.7 \\
\hline Married & 737 & 3.1 \\
\hline Divorced & 15 & Percent (\%) \\
\hline Widow/Widower & 436 & 16.8 \\
\hline Health care service coverage & Frequency (n) & 82.8 \\
\hline Not Insured/Paid Patients & 222 & 0.5 \\
\hline National Health Insurance Scheme (NHIS)) & 1095 & Percent (\%) \\
\hline Private Insurance & 6 & 37.2 \\
\hline Occupation/Employment & Frequency (n) & 29.4 \\
\hline Unemployed/Housewife & 492 & 7.8 \\
\hline Farmer & 389 & 2.9 \\
\hline Trader & 103 & 3.7 \\
\hline Teaching & 39 & 4.2 \\
\hline Civil Servant & 49 & 5.1 \\
\hline Retired Civil Servant & 55 & 1.9 \\
\hline Artisans/Trade Workers & 68 & 7.8 \\
\hline Self Employed & 25 & \\
\hline Students & 103 & \\
\hline
\end{tabular}

Others = Severe Vernal Conjunctivitis, Uveitis and Phthisis Bulbi.

\section{Prevalence and causes of visual impairment}

Out of the 4659 new cases reviewed, 1323 were included in the study which gave us an overall calculated visual impairment prevalence of $28.4 \%$. The distributions of prevalence and causes of visual impairment in the study are shown in Tables $2 \& 3$ respectively. The causes of visual impairment among Health Care Services Coverage are depicted in Figure 1.

Table 2: Distribution of Prevalence and Causes of Visual impairment and types of Refractive Error.

\begin{tabular}{|c|c|c|}
\hline \multicolumn{3}{|c|}{ Summary } \\
\hline Prevalence of Types of Visual Impairment & Frequency (n) & Percent (\%) \\
\hline No/Mild Visual Impairment & 35 & 2.6 \\
\hline Moderate Visual Impairment (MVI) & 841 & 63.6 \\
\hline Severe Visual Impairment (SVI) & 65 & 4.9 \\
\hline Blindness & 382 & 28.9 \\
\hline Prevalence of Causes of Visual Impairment (Primary Diagnosis) & Frequency (n) & Percent (\%) \\
\hline Uncorrected Refractive Error & 260 & 19.7 \\
\hline Others & 12 & 0.9 \\
\hline Amblyopia & 1 & 0.1 \\
\hline Cataract & 664 & 50.2 \\
\hline Glaucoma & 211 & 15.9 \\
\hline ARMD/Macular Degeneration & 20 & 1.5 \\
\hline Chorioretinal Degeneration & 26 & 2.0 \\
\hline Corneal Related Disorders & 129 & 9.8 \\
\hline Trachoma & 0 & 0.0 \\
\hline Onchocerciasis & 0 & 0.0 \\
\hline Prevalence of Refractive Error & Frequency (n) & Percent (\%) \\
\hline Anisometropia & 14 & 1.1 \\
\hline Presbyopia & 38 & 2.9 \\
\hline Myopia & 330 & 24.9 \\
\hline
\end{tabular}


JOJ Ophthalmology

\begin{tabular}{|c|c|c|}
\hline Hyperopia & 456 & 34.5 \\
\hline Astigmatism & 485 & 36.7 \\
\hline
\end{tabular}

Others $=$ Severe Vernal Conjunctivitis, Uveitis and Phthisis Bulbi.

Table 3: Distribution of the Causes of Visual Impairment.

\begin{tabular}{|c|c|c|c|c|c|c|c|c|c|}
\hline & \multicolumn{8}{|c|}{ Primary Diagnosis (Causes of Visual Impairment) } & \multirow[b]{2}{*}{ TT } \\
\hline & $\mathrm{RE}$ & Others & AMB & Cataract & Glaucoma & ARMD & ChRD & CRD & \\
\hline $\mathrm{BN}$ & $\begin{array}{c}3 \\
(0.2 \%)\end{array}$ & $\begin{array}{c}3 \\
(0.2 \%)\end{array}$ & $\begin{array}{c}1 \\
(0.1 \%)\end{array}$ & $\begin{array}{c}203 \\
(15.3 \%)\end{array}$ & $\begin{array}{c}120 \\
(9.1 \%)\end{array}$ & $\begin{array}{c}8 \\
(0.6 \%)\end{array}$ & $\begin{array}{c}9 \\
(0.7 \%)\end{array}$ & $\begin{array}{c}35 \\
(2.6 \%)\end{array}$ & $\begin{array}{c}382 \\
(28.9 \%)\end{array}$ \\
\hline MVI & $\begin{array}{c}204 \\
(15.4 \%) \\
\end{array}$ & $\begin{array}{c}9 \\
(0.7 \%)\end{array}$ & $\begin{array}{c}0 \\
(0.0 \%)\end{array}$ & $\begin{array}{c}438 \\
(33.1 \%)\end{array}$ & $\begin{array}{c}74 \\
(5.6 \%)\end{array}$ & $\begin{array}{c}11 \\
(0.8 \%)\end{array}$ & $\begin{array}{c}16 \\
(1.2 \%)\end{array}$ & $\begin{array}{c}89 \\
(6.7 \%) \\
\end{array}$ & $\begin{array}{c}841 \\
(63.6 \%)\end{array}$ \\
\hline NVI & $\begin{array}{c}34 \\
(2.6 \%)\end{array}$ & $\begin{array}{c}0 \\
(0.0 \%)\end{array}$ & $\begin{array}{c}0 \\
(0.0 \%)\end{array}$ & $\begin{array}{c}1 \\
(0.1 \%)\end{array}$ & $\begin{array}{c}0 \\
(0.0 \%)\end{array}$ & $\begin{array}{c}0 \\
(0.0 \%)\end{array}$ & $\begin{array}{c}0 \\
(0.0 \%)\end{array}$ & $\begin{array}{c}0 \\
(0.0 \%)\end{array}$ & $\begin{array}{c}35 \\
(2.6 \%)\end{array}$ \\
\hline SVI & $\begin{array}{c}19 \\
(1.4 \%)\end{array}$ & $\begin{array}{c}0 \\
(0.0 \%)\end{array}$ & $\begin{array}{c}0 \\
(0.0 \%)\end{array}$ & $\begin{array}{c}22 \\
(1.7 \%)\end{array}$ & $\begin{array}{c}17 \\
(1.3 \%)\end{array}$ & $\begin{array}{c}1 \\
(0.1 \%)\end{array}$ & $\begin{array}{c}1 \\
(0.1 \%)\end{array}$ & $\begin{array}{c}5 \\
(0.4 \%)\end{array}$ & $\begin{array}{c}65 \\
(4.9 \%)\end{array}$ \\
\hline TT & $\begin{array}{c}260 \\
(19.7 \%)\end{array}$ & $\begin{array}{c}12 \\
(0.9 \%)\end{array}$ & $\begin{array}{c}1 \\
(0.1 \%)\end{array}$ & $\begin{array}{c}664 \\
(50.2 \%)\end{array}$ & $\begin{array}{c}211 \\
(15.9 \%)\end{array}$ & $\begin{array}{c}20 \\
(1.5 \%)\end{array}$ & $\begin{array}{c}26 \\
(2.0 \%)\end{array}$ & $\begin{array}{c}129 \\
(9.8 \%)\end{array}$ & 1323 \\
\hline
\end{tabular}

Others = Severe Vernal Conjunctivitis, Uveitis and Pthisis Bulbi.

$\mathrm{BN}=$ Blindness; $\mathrm{NVI}=$ Normal Visual Impairment; MVI= Moderate Visual Impairment; SVI= Severe Visual Impairment; RE= Refractive Error; $\mathrm{AMB}=$ Amblyopia'; $\mathrm{ARMD}=$ Age Related Macular Degeneration; $\mathrm{ChRD}=$ Chorioretinal Degeneration; $\mathrm{CRD}=$ Corneal Related Degeneration; TT= Total.

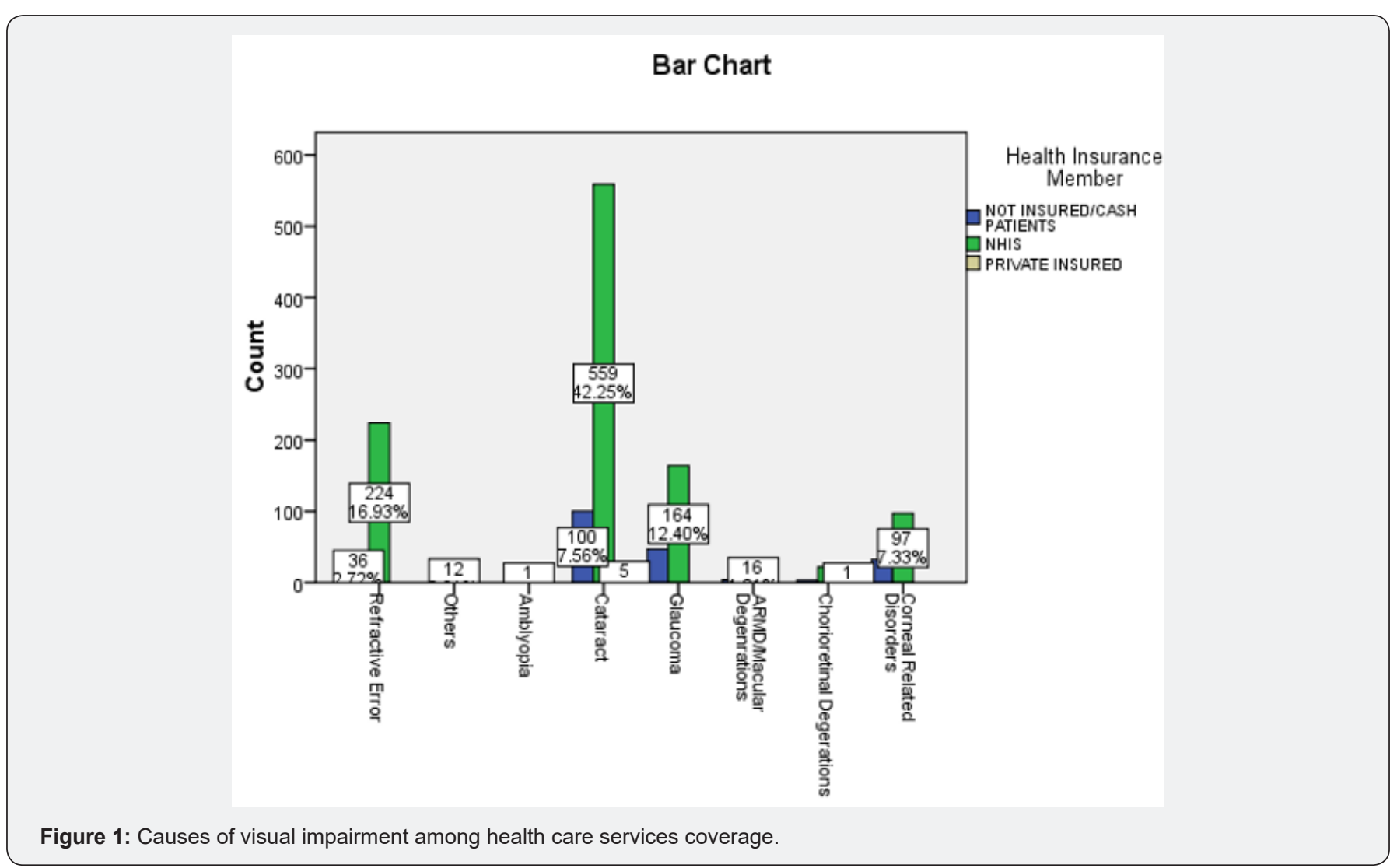

\section{Prevalence and causes of visual impairment among age group}

The distribution of prevalence of visual impairment among age groups is depicted in Figure 2. This distribution of visual impairment among age groups was significant at chi square $=$ 2.039E2, $p<0.01$. Uncorrected Refractive Error was the major cause of visual impairment among the 6-20 (5.2\%) age group, followed by the $41-50$ (4.5\%), 31-40 (2.9\%), and the 21-30 (1.8\%) age groups respectively. Cataract was the main cause of visual impairment among the older ages. The prevalence of Glaucoma was observed to increase with increasing age: $0.5 \%$ in the $6-20$ age group steadily to $9.9 \%$ in the 61 and above age group. A case of Amblyopia (0.1\%) was recorded in the 6-20 age group. 


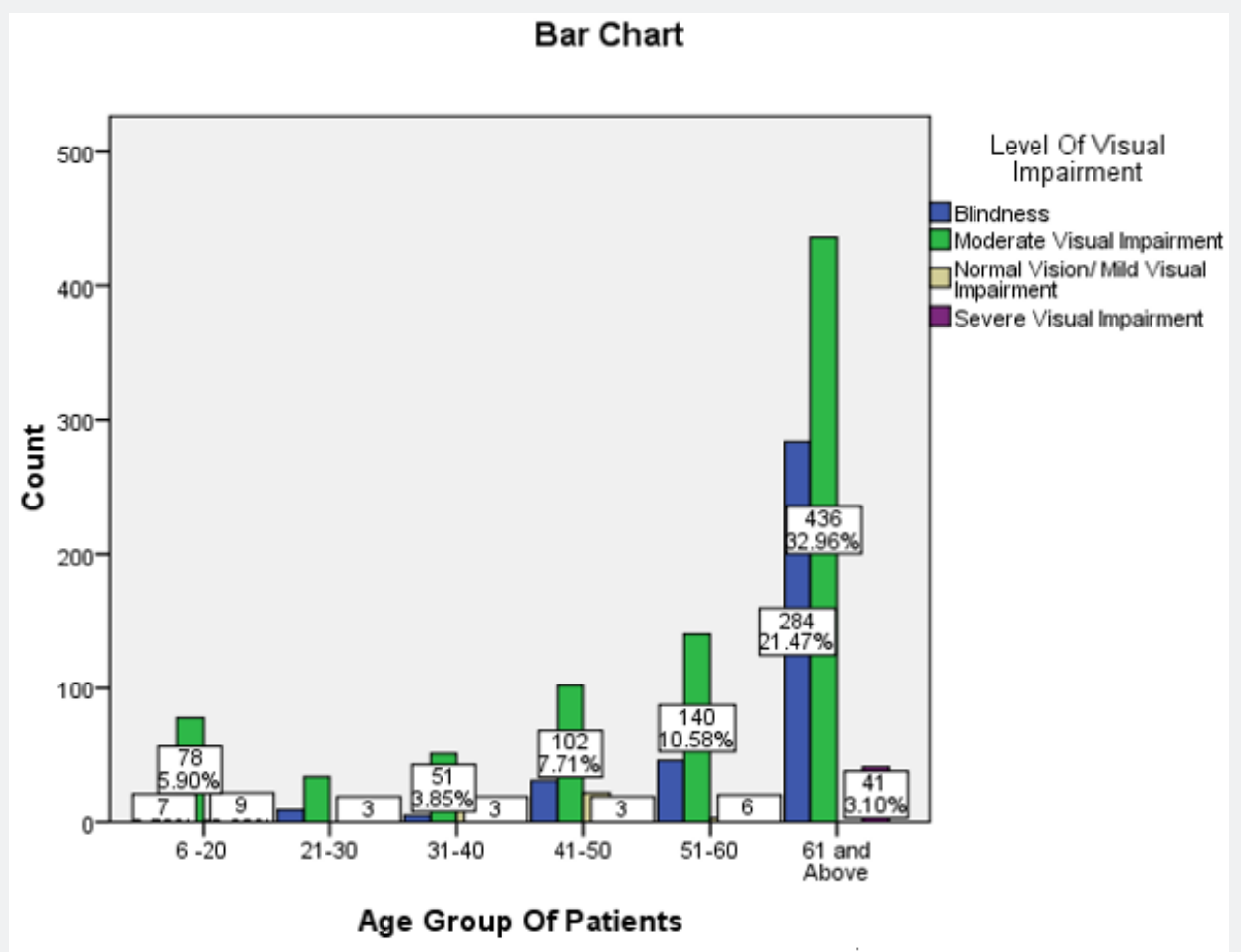

Figure 2: Distribution of types of visual impairment among age group.

\section{Prevalence of visual impairment among gender}

The distributions of levels and causes of visual impairment by gender are depicted in Figures 3 \& 4 respectively.

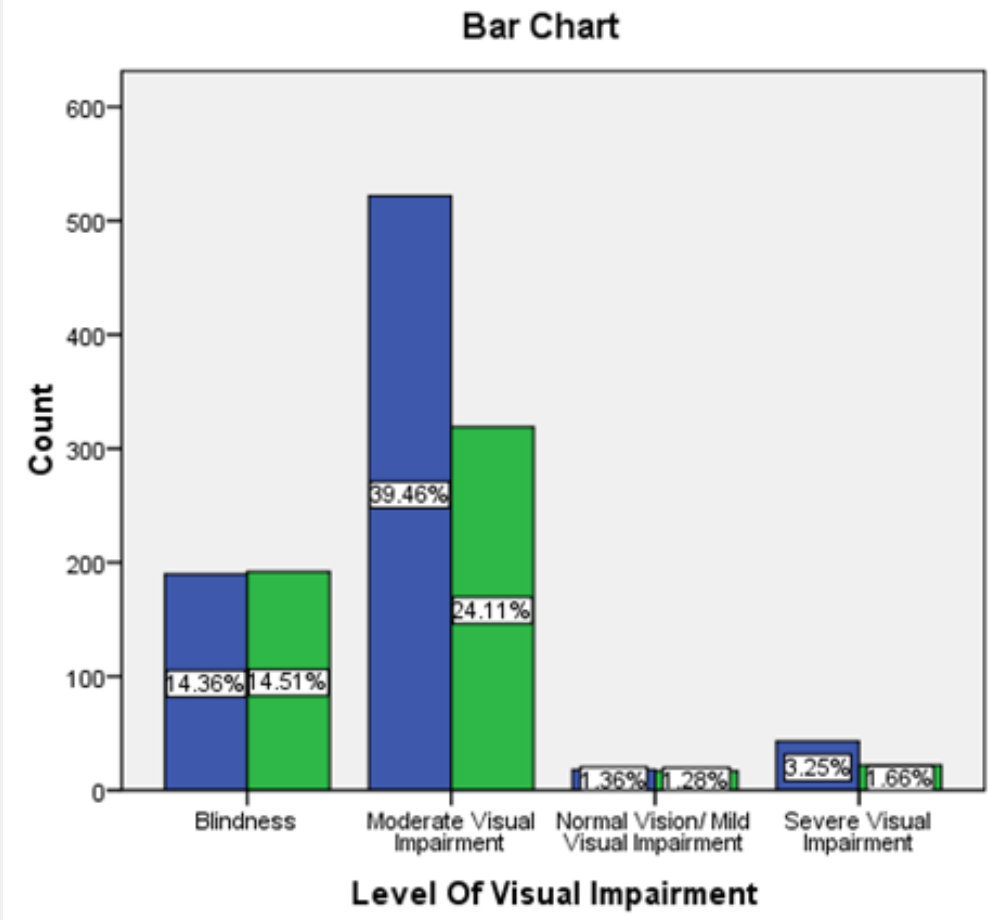

Gender Of Patients

口Female

$\square$ Male

Figure 3: Distribution of types of visual impairment among gender. 


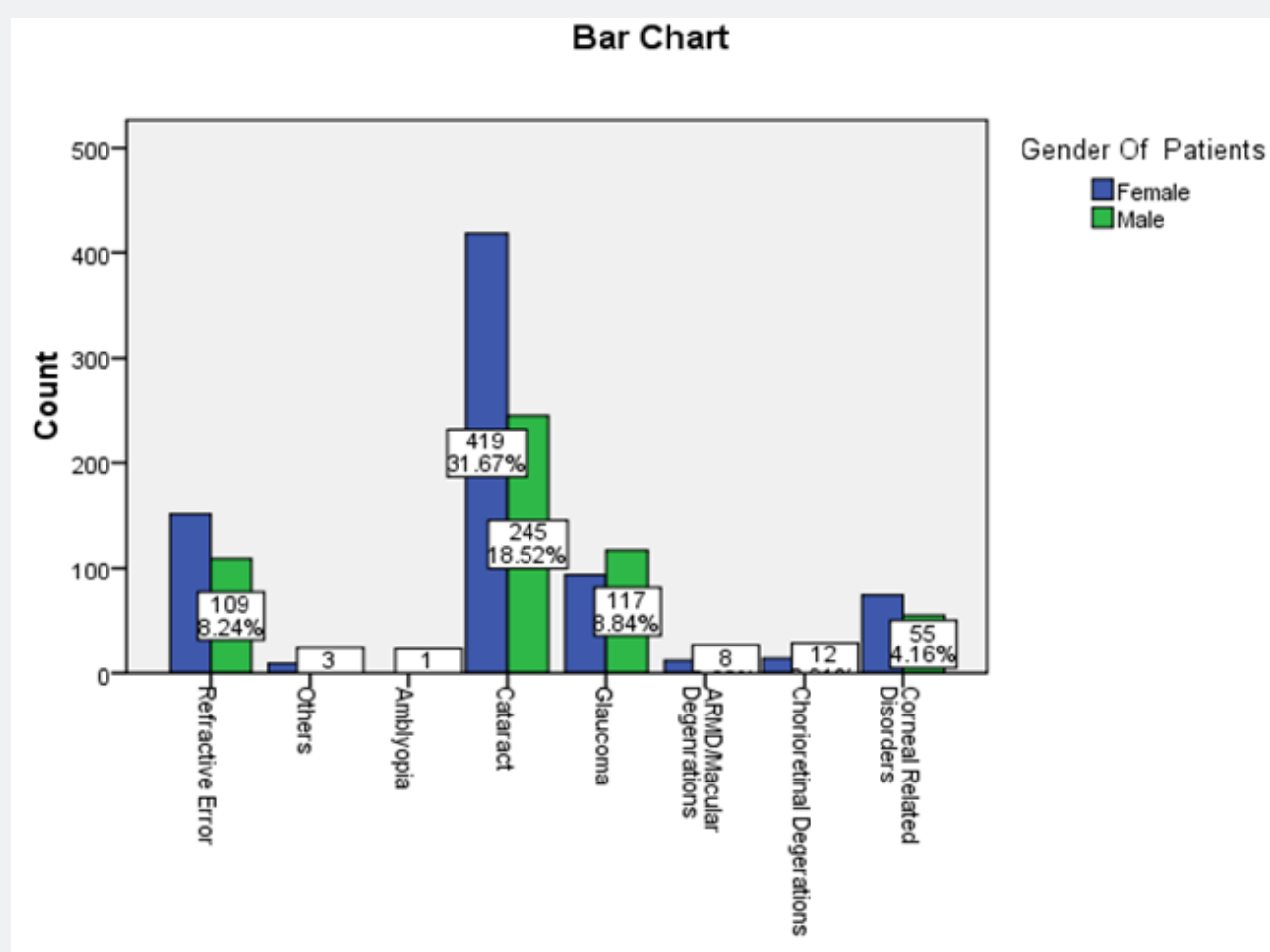

Figure 4: Causes of visual impairment among gender.

\section{Prevalence of visual impairment among marital status}

Age and gender greatly influence marital status [12]. In the Bolgatanga municipal, females generally marry earlier than males [12]. Females globally, and in Ghana had been observed to live longer than their male counterparts [3]. This made them vulnerable to Visual Impairment (VI) than males $[3,4]$. The results showed that married persons recorded more visual impairment 55.7\% (MSVI 37.1\% and blindness 16.5\%) and 2.1\% near low vision, fol- lowed by the widows/widowers $33.0 \%$ (MSVI 21.7\% and blindness $11.3 \%$ ), and $0.1 \%$ near low vision. The divorced persons had the least record of $1.1 \%$ (MSVI $0.7 \%$ and blindness $0.3 \%$ ) and $0.2 \%$ near low vision.

\section{Causes of visual impairment among marital status}

The causes of visual impairment among marital status are shown in Table 4.

Table 4: The causes of Visual Impairment among Marital Status.

\begin{tabular}{|c|c|c|c|c|c|}
\hline & Divorced & Married & Single & Widow / Widower & TT \\
\hline RE & $5(0.4 \%)$ & $140(10.6 \%)$ & $92(7.0 \%)$ & $23(1.7 \%)$ & $260(19.7 \%)$ \\
\hline Others & $1(0.1 \%)$ & $3(0.2 \%)$ & $4(0.3 \%)$ & $4(0.3 \%)$ & $12(0.9 \%)$ \\
\hline AMB & $0(0.0 \%)$ & $0(0.0 \%)$ & $1(0.1 \%)$ & $0(0.0 \%)$ & $1(0.1 \%)$ \\
\hline Cataract & $4(0.3 \%)$ & $356(26.9 \%)$ & $9(0.7 \%)$ & $295(22.3 \%)$ & $664(50.2 \%)$ \\
\hline Glaucoma & $4(0.3 \%)$ & $136(10.3 \%)$ & $16(1.2 \%)$ & $55(4.2 \%)$ & $211(15.9 \%)$ \\
\hline ARMD & $0(0.0 \%)$ & $6(0.5 \%)$ & $4(0.3 \%)$ & $10(0.8 \%)$ & $20(1.5 \%)$ \\
\hline ChRD & $1(0.1 \%)$ & $16(1.2 \%)$ & $2(0.2 \%)$ & $7(0.5 \%)$ & $26(2.0 \%)$ \\
\hline CRD & $0(0.0 \%)$ & $80(6.0 \%)$ & $7(0.5 \%)$ & $42(3.2 \%)$ & $129(9.8 \%)$ \\
\hline TT & $15(1.1 \%)$ & $737(55.7 \%)$ & $135(10.2 \%)$ & $436(33.0 \%)$ & $1323(100.0 \%)$ \\
\hline
\end{tabular}

Others = Severe Vernal Conjunctivitis, Uveitis and Pthisis Bulbi; BN= Blindness; NVI= Normal Visual Impairment; MVI= Moderate Visual Impairment; SVI= Severe Visual Impairment; RE= Refractive Error; AMB= Amblyopia'; ARMD= Age Related Macular Degeneration; ChRD= Chorioretinal Degeneration; $\mathrm{CRD}=$ Corneal Related Degeneration; TT=Total. 
Prevalence of visual impairment among occupation/ type of employment

About $(n=492,37.2 \%$ ) cases of visual impairment were found among Housewives/Unemployed of which 18.2\% had MVI, 16.6\% had blindness, $2.3 \%$ had SVI and $0.1 \%$ had near low vision. This was followed by Farmers who had ( $\mathrm{n}=389,29.4 \%)$ of the visual impairment cases where $19.3 \%$ had MVI, 9.1\% blindness, $0.9 \%$ SVI and $0.1 \%$ had near low vision. Students and Traders both had the same number of cases ( $\mathrm{n}=103,7.8 \%$ ) where 9.8\% MVI was found in Traders whereas 6.5\% was found among Students; $0.7 \%$ SVI in Students and $0.4 \%$ in Traders, and $0.5 \%$ blindness in Students and $0.4 \%$ blindness among Traders. The Self Employed had the least cases of visual impairment of ( $n=25,1.9 \%)$ of which MVI form the majority with $1.2 \%$, and blindness and near low vision each were $0.3 \%$. The distribution of prevalence of visual impair- ment among types of Occupation/Employment was significant at chi square $=3.381 \mathrm{E} 2 \mathrm{p}<0.01$.

\section{Causes of visual impairment among types of occupa- tion/ employment}

323 Cataract cases were found among Housewives/Unemployed, followed by Farmers with 207 cases, Traders 49 cases, Retired and Artisans both had 27 cases each.72 cases of uncorrected refractive error were noticed among Students, followed by 38 cases in Farmers, 30 cases in Traders and 29 in Civil Servants. 84 cases of Glaucoma were found in Housewife/Unemployed, 79 in Farmers, Students-Traders-Artisans each had 10 cases while the Retired had 8 cases. 48 cases of Corneal Related Disorders were found among Farmers, followed by 41 cases in Housewife /Unemployed, 12 cases in Traders and 9 cases in Artisans.

\section{Distribution of uncorrected refractive error and level of visual impairment}

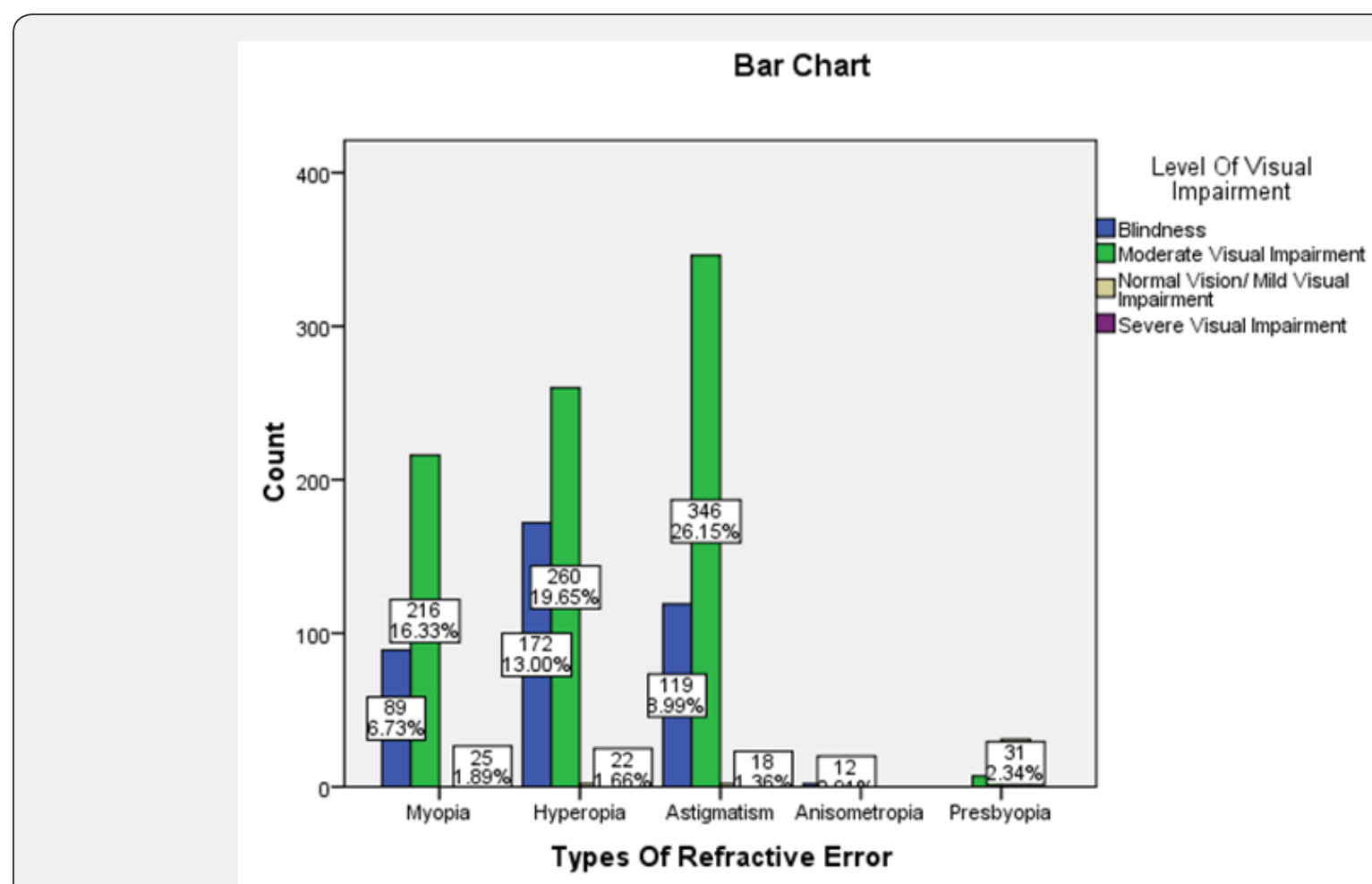

Figure 5: Distribution of types of refractive error among level of visual impairment.

The distribution of Refractive Error among Level of Visual Impairment is shown in Figure 5. The distribution of Level of Visual Impairment among types of refractive error was significant chi square $=9.794 \mathrm{E} 2, \mathrm{p}<0.01$.

\section{Discussion}

\section{Prevalence of visual impairment}

Of the 4659 new cases reviewed, 1323 were included in our study which gave us an overall calculated visual impairment prevalence of $28.4 \%$. This was slightly lower than what was reported by Ansah, in the Juaben study where visual impairment prevalence of 31.9\% (MSVI 28.2\% and blindness 3.7\%) [2] was reported. This difference may be because, unlike our study, all cases (old and new) seen within the study period, were included in the Juaben study. The mean age of our study was $60.44 \pm 19.663$ years. This showed that visual impairment in the municipality was common among the older persons. This agreed with the global trend where, increasing age and population, coupled with higher life expectancy have been noted to be associated with increasing prevalence rates of visual impairment [3]. 
The estimated prevalence of low vision and blindness was $68.5 \%$ and $28.9 \%$ respectively. These were relatively higher than those reported in most studies done in Ghana. In two hospital-based studies: in determining the pattern of ocular conditions among patients who attended the Salvation Army Eye Clinic in the Ashanti region of Ghana, Mireku, reported $40.73 \%$ and $15.01 \%$ prevalence rates of low vision and blindness respectively [14] and in determining the prevalence and causes of visual impairment and blindness among eye clinic patients at the Juaben Hospital, Ansah reported 28.2\% and 3.7\% prevalence rates of visual impairment and blindness respectively [2] whiles in a population-based study conducted by Guzek et al. [15] in the Volta region, they reported $13.4 \%$ and $2.8 \%$ prevalence rates of visual impairment and blindness respectively [15] and $17.1 \%$ and $1.2 \%$ prevalence rates of visual impairment and blindness was reported in the Tema Eye survey by Budenz et al. [16] We found the prevalence of normal/mild visual impairment to be $2.6 \%$, which was mainly due to Presbyopia (2.5\%).

\section{Causes of visual impairment}

We found, Cataract 664 (50.2\%), Uncorrected Refractive Errors 260 (19.7\%), Glaucoma 211 (15.9\%) and Corneal Related Disorders $129(9.8 \%)$ as the main causes of visual impairment. The other causes were: Chorioretinal degeneration $26(2.0 \%)$, ARMD/Macular degeneration 20 (1.5\%) and Others 12(0.9\%). This trend is consistent with that reported by Ansah in the Juaben hospital study where Cataract (39.05\%), uncorrected refractive error $(21.60 \%)$ and glaucoma (18.34\%) were reported as the leading causes of visual impairment [2]. However, the Ghana blindness and visual impairment study observed and reported a different trend which is consistent with the observation made in the global estimates of prevalence of visual impairment in the Western Sub-Saharan region [3], where uncorrected refractive error(44.4\%), cataract (42.2\%), posterior segment(8.9\%) and glaucoma and corneal opacity each(2.2\%) [5] were the main causes of visual Impairment. In determining the pattern of ocular conditions among patients who attended the Salvation Army Eye Clinic in the Ashanti region of Ghana, Mireku reported cataract $(24.40 \%)$, glaucoma $(9.70 \%)$ and uncorrected refractive error (8.90\%) [14] as the main causes of visual impairment which is a similar trend observed by Guzek et al. [15] in their work in the Volta region of Ghana [15].

The major causes of blindness found in our study were: Cataract 15.3\%, Glaucoma (9.1\%), and Corneal Related Disorders (2.6\%). This is similar to what was reported in the Ghana Blindness and Visual impairment study where cataract (54.8\%), glaucoma $(19.4 \%)$ posterior segment $(12.9 \%)$, and corneal opacity $(11.2 \%)$ were the main causes of blindness [5]. A clinic-based survey of blindness and eye disease in Cambodia also reported similar trend of causes of blindness [21] save that, in our study, Trachoma, Childhood blindness and Onchocerciasis were not found. However, Ansah [2], reported Glaucoma (65.91\%), Cataract $(22.73 \%)$, as the causes of blindness similar to what was reported in a population-based study in the Wenchi District by Moll et al. [9], Whiles Oye et al. [10] reported pos 7 terior segment diseases, cataract and optic atrophy as the major causes of blindness. These differences could be because; our study was hospital-based, hence bias to health seeking persons thus high records of case presentations. There were no presentation of trachoma and onchocerciasis in our study despite the Upper East region lying within the Meningitis Belt of Africa as well as the Savannah blinding Onchocerciasis Belt of West Africa [11,12]. This observation could be attributed to the success of the antibiotic distribution and treatment in eliminating these two infectious eye diseases, to which a recent announcement by WHO, declared Ghana the first country within WHO Africa Region to eliminate trachoma [23].

\section{Visual impairment: association with age and gender}

Age and gender each were found to be associated with visual impairment in our study at $\mathrm{p}<0.01$. This observation is consistent with what was reported in the global estimates of prevalence of visual impairment [3], as well as other surveys across Africa and Asia [8-10], where higher visual impairment prevalence rates have been reported for the aged. This increase in prevalence could be because most of the causes of visual impairment are chronic and age-related. In all age groups, we found more females than males and this difference was significant at $p=0.044$. This could be attributed to the fact that, females have been reported to have relative high longevity than males $[3,4]$. Thus, older age and being a female are high-risk factors of visual impairment in the Bolgatanga Municipality of the Upper East region of Ghana.

\section{Visual impairment association with occupation/em- ployment}

Employment related disparities exist in both develop and developing countries [12]. In an exploratory quantitative study to understand the relationships among disability, gender and employment in Northern Ghana by Naami A, of which Upper East was part, it was reported that, many persons with disabilities were unemployed, and the majority were women [12]. This was evident in our study where the majority of people with visual impairment were in the unemployed/housewife category, of which the majorities were females. The majority of farmers from our study were females whereas in the study to determine the prevalence and causes of visual impairment and blindness among cocoa farmers in Ghana by Boadi et al. [24] more male cocoa farmers were reported. We also recorded more male artisans /trade workers than females which were consistent with the male - female ratio of mechanics reported in the Cape Coast metropolis by Abu et al. [19] in their work. We found cataract (which was more among the unemployed/housewife) to be the major cause of visual impairment followed by uncorrected refractive errors (which were more among students), glaucoma, and corneal related disorders (which were more among Farmers). Boadi et al. [24] in the work, prevalence and causes of visual impairment and blindness among cocoa farmers in Ghana, they reported anterior segment disorders 
(pterygium 23.7\%, allergic conjunctivitis 9.7\% and corneal scar/ opacity $6.1 \%$ ) and cataract as the main causes of visual impairment: with Posterior segment conditions and uncorrected refractive errors as the Major Causes of Low Vision (MSVI) and legal blindness. In a study to assess ocular health and safety among mechanics in the Cape Coast metropolis by Abu et al. [19] refractive errors, cataracts, and macular scars were reported as the causes of visual impairment. MVI was the highest form of visual impairment followed by Blindness, and SVI among the various types of occupation with the near low vision being the least in our study.

\section{Visual impairment and refractive error}

Refractive error was the second cause of Visual Impairment (VI) in our study. However, Abokyi et al. [1] in their work visual impairment attributed to uncorrected refractive error among the Ghanaian youth, reported refractive error and corneal opacity to be the main causes of VI and corneal opacity as the main cause of blindness. In the prevalence and causes of blindness and low vision among adults in Fiji, Ramke et al. [25] reported uncorrected refractive error as the cause of low vision. A total of 29 (6.7\%) respondents with refractive errors as the main cause of VI were reported by Abu et al. [19] among mechanics in the Cape Coast Metropolis, whereas we recorded $260(19.7 \%)$ cases of uncorrected refractive. The observed distribution of types of refractive error by Abu et al. [19] was astigmatism, hyperopia and myopia which is consistent with what we found in our work. However, in the pattern of ocular conditions among patients attending an eye clinic in Ghana study by Mireku [14], myopia, astigmatism and hyperopia was the trend of distribution of types of refractive error observed. We found the prevalence of normal/mild visual impairment to be $2.6 \%$, which was mainly due to Presbyopia (2.5\%). This prevalence of Presbyopia was lower than that reported in several studies across Africa: $25.11 \%$ prevalence of presbyopia was reported by Kahaki et al. [17] in Mbeere District of Kenya, 68.1\% reported by Kumah et al. [18] in Kumasi among public senior high school teachers, $25.9 \%$ reported by Abu et al. [19] among mechanics in cape coast and $70.9 \%$ as reported by Emerole et al. in Oweiri Nigeria [20]. The reason for the differences in prevalence of Presbyopia in our study and the other studies, may be due to the differences in the type of population studied.

\section{Limitations}

A major limitation of this study was that, as a hospital-based study, findings and comparisons related to visual impairment do not represent the true state of the entire municipality, since those who were included in the study were those who could afford eye care.

\section{Recommendations}

Uncorrected refractive error being the second cause of VI in the general population and main cause of VI among younger age, aside cataract (which is covered under the NHIS), a community and School Eye Screening of children for refractive errors and ed- ucation on awareness and benefits of spectacle corrections so as to remove cultural barriers to compliance is highly recommended.

\section{Conclusion}

There is a high prevalence of visual impairment in the Bolgatanga Municipality with cataract, uncorrected refractive error, glaucoma, and corneal related disorders, as the major causes. Older age, unemployment, being a female (gender) and being a widow/widower (marital status) are the socio-demographic risk factors identified.

\section{Acknowledgements}

Our gratitude goes to the Navrongo Health Research Centre, Institutional Review Board for the ethical clearance and approval to carry out the work. Also, to the administration of the Bolgatanga Presbyterian Regional Eye Hospital for granting us access to patient data and the facility as a study center. Special thanks to Dr. Albert Kum Brown, the Optometrist at the Presbyterian Regional Hospital, Bolgatanga, also to the Optician, the record staff and all who have assisted in ways to the success of this work. A special thanks to faculty members of the School of Advanced Education, Research and Accreditation, and Dr. Kwaku Antwi Osei, for commenting and shaping the manuscript.

\section{References}

1. Abokyi S, Ilechie A, Nsiah P, Darko Takyi C, Abu EK, et al. (2016) Visual impairment attributable to uncorrected refractive error and other causes in the Ghanaian youth: The University of Cape Coast Survey. J Optom 9(1): 64-70.

2. Ansah DO (2017) Prevalence and Causes of Visual Impairment among Patients in Juaben Hospital Eye Clinic, Ghana. M J Opht 2(2): 1-17.

3. Flaxman SR, Bourne RR, Resnikoff S, Ackland P, Braithwaite T (2017) Global causes of blindness and distance vision impairment 1990-2020: A systematic review and meta-analysis. Lancet Glob Health 5(12): e1221-e1234.

4. World Health Organization (2013) A Global Action Plan 2014-2019. Draft action plan for the prevention of avoidable blindness and visual impairment 2014-2019, towards a universal eye health. Sixty-Sixth World Health Assembly A66/11, Provisional Agenda Item 13.4, WHO, Geneva.

5. International Agency for the Prevention of Blindness (2015) Ghana Blindness and Visual Impairment Study.

6. World Health Organization (2016) International Statistical Classification of Diseases and Related Health Problems ( $\left.10^{\text {th }} \mathrm{Edn}\right)$.

7. Sherwin JC, Lewallen S, Courtright P (2012) Blindness and visual impairment due to uncorrected refractive error in sub-Saharan Africa: review of recent population-based studies. Br J Ophthalmol 96(7): 927-930.

8. Oduntan O, Mashige K, Hansraj R, Ovenseri Ogbomo G (2015) Strategies for reducing visual impairment and blindness in rural and remote areas of Africa. Aveh 74(1): 25.

9. Moll AC, Van der Linden AJ, Hogeweg M, Schader WE, Hermans J, et al. (1994) Prevalence of blindness and low vision of people over 30 years in the Wenchi district, Ghana, in relation to eye care programmers. Br J Ophthalmol 78(4): 275-279. 
10. Oye JE, Kuper H (2007) Prevalence and causes of blindness and visual impairment in Limbe urban area, South West Province, Cameroon. Br J Ophthalmol 91(11): 1435-1439.

11. Ghana Health Directorate (2017) Upper East Regional Health Directorate.

12. Ghana Statistical Service (2010) Ghana Provisional Census Results.

13. Council for International Organizations of Medical Sciences (2009) International Ethical Guidelines for Epidemiological Studies. p. 96.

14. Agyemang Mireku F (2017) Pattern of Ocular Conditions among Patients Attending an Eye Clinic in Ghana. Optom Open Access 2(1): 122.

15. Guzek JP, Anyomi FK, Fiadoyor S, Nyonator F (2005) Prevalence of Blindness in People Over 40 Years in the Volta Region of Ghana. Ghana Med J 39(2): 55-62.

16. Budenz DL, Bandi JR, Barton K, Nolan W, Herndon L (2012) Blindness and Visual Impairment in an Urban West African Population: The Tema Eye Survey. Ophthalmology 119(9): 1744-1753.

17. Kimani K, Lindfield R, Senyonjo L, Mwaniki A, Schmidt E (2013) Prevalence and Causes of Ocular Morbidity in Mbeere District, Kenya: Results of a Population-Based Survey. PLoS One 8(8): e70009.

18. Kumah DB, Lartey SY, Amoah Duah K (2011) Presbyopia among Public Senior High School Teachers in the Kumasi Metropolis. Ghana Med J 45(1): $27-30$

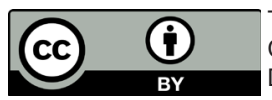

This work is licensed under Creative

Commons Attribution 4.0 License

DOI: $10.19080 / J O J O .2019 .07 .555718$
19. Abu EK, Boadi Kusi SB, Opuni PQ Kyei S, Owusu Ansah A, et al. (2016) Ocular Health and Safety Assessment among Mechanics of the Cape Coast Metropolis, Ghana. J Ophthalmic Vis Res 11(1): 78-83.

20. Emerole CG, Nneli RO, Osim EE (2014) Presbyopia: Prevalence, distribution and determinants in Owerri, Nigeria. J Exp Clin Anat 13: 21-25.

21. Thomson I (1997) A clinic-based survey of blindness and eye disease in Cambodia. Br J Ophthalmol 81: 578-580.

22. Naami A (2015) Disability, gender, and employment relationships in Africa: The case of Ghana. Afr J Disabil 4(1): 95.

23. World Health Organization Africa (2018) Ghana eliminates trachoma, freeing millions from suffering and blindness.

24. Boadi Kusi SB, Hansraj R, Khathutshelo M, Osafo Kwaako A, Azukallechie A, et al. (2017) Prevalence and Causes of Visual Impairment and Blindness among Cocoa Farmers in Ghana. Ophthalmic Epidemiol 24(1): 17-23.

25. Ramke J, Brian G, Maher L, Qalo Qoqonokana M, Szetu J (2012) Prevalence and causes of blindness and low vision among adults in Fiji. Clin Exp Ophthalmol 40(5): 490-496.

\section{Your next submission with Juniper Publishers will reach you the below assets}

- Quality Editorial service

- Swift Peer Review

- Reprints availability

- E-prints Service

- Manuscript Podcast for convenient understanding

- Global attainment for your research

- Manuscript accessibility in different formats

( Pdf, E-pub, Full Text, Audio)

- Unceasing customer service

Track the below URL for one-step submission https://juniperpublishers.com/online-submission.php 